\title{
Exploring the communication experiences of international nurses who participated in a 13-week accent modification program
}

\author{
Hanna A. Belay* \\ Saint Cloud State University, United States
}

Received: October 8, 2018

DOI: $10.5430 /$ jnep.v9n4p106
Accepted: December 12, 2018 Online Published: December 28, 2018

URL: https://doi.org/10.5430/jnep.v9n4p106

\begin{abstract}
Objective: This qualitative study explored the personal interactions of the nurses with patients, families, providers and other staff members after taking part in accent modification program.

Methods: Hermeneutic Interpretive Phenomenology influenced by philosopher Martin Heidegger provided the philosophical underpinnings to guide this exploration of the communication experiences of international nurses about four to eight months after completion of a 13-week accent modification program.

Results: The following six themes emerged from the data: I have the tool, I am self-assured, I speak with intention, I want to involve, My accent is part of who I am, and I am not an introvert.

Conclusions: The findings of this study suggested that an accent modification program improves communication skills of international nurses regardless of age, gender, country of origin, and length of stay in the U.S. It is reassuring to employers who realize that there is a potentially effective intervention to improve and enhance linguistic competence of their current international nurses.
\end{abstract}

Key Words: Accent, Modification, Reduction, International, Nurses, Language, Barriers, Communication

\section{FOCUS OF INQUIRY}

International nurses are a significant and integral part of the healthcare workforce in the United States (U.S.) and account for $12 \%$ to $15.2 \%$ of the U.S. nursing workforce. ${ }^{[1,2]}$ With the growing shortage of nurses, the recruitment and employment of international nurses will continue to be one of the strategies to alleviate the shortage. ${ }^{[3-7]}$

International nurses face many unique and complex challenges as they navigate through the U.S. healthcare environment. Language and communication barriers are frequently daunting issues facing international nurses. These barriers have been reported as a concern by hospital staff, physicians, and hospital administrators. ${ }^{[2,3,8]}$ International nurses face both communication and socio-cultural issues in clinical settings. ${ }^{[2,9]}$ Literature indicates that the greatest linguistic challenge for international nurse is clarity of speech due to speaking English with an accent. ${ }^{[2]}$ Accented speech influenced the intelligibility and comprehensibility of speech and consequently led to communication breakdown. ${ }^{[2,10]}$ A leading cause of sentinel events and most medical errors have been identified as a breakdown in communication. ${ }^{[1]}$ Therefore, to avoid any real and potential threats to patient safety and quality of care, it is imperative to support international

*Correspondence: Hanna A. Belay; Email: hbelay@stcloudstate.edu; Address: Saint Cloud State University, United States. 
nurses improve their linguistic skills. ${ }^{[2,12,13]}$

An accent modification program is designed to help individuals who speak English with a foreign accent to establish new habits which will enable them to pronounce English words correctly. ${ }^{[14]}$ There are rules that must be learned to modify one's accent. The study conducted by Carr \& DeKemelIchikawa (2012) ${ }^{[15]}$ found that nursing students who speak English with heavy accent showed improvement in speech intelligibility after participating in accent modification program. Similarly, Belay $(2012)^{[16]}$ conducted a pre-posttest design study to examine the effectiveness of a 13-week accent modification program. The findings of this study show statistically significant reduction of pronunciation errors ( $p$ $<.0001$ ) in the areas of carrier sentences, passage readings, and delivering shift report.

\subsection{Rationale for the study}

Except for anecdotal evidence and testimonials, no literature was identified that explored the lasting effect of nurses after participating in an accent modification program. This qualitative study provided a deeper understanding of how the international nurses' daily communication with patients, physicians, and others was affected after participating in the program. Hermeneutic Interpretive Phenomenology influenced by philosopher Martin Heidegger provided the philosophical underpinnings to guide this exploration of the communication experiences of international nurses about four to eight months after completion of a 13-week accent modification program. ${ }^{[17]}$

\subsection{Problem of study/statement of purpose}

The purpose of this qualitative study was to explore the experiences of international nurses surrounding communication skills they learned from the 13-week accent modification program. The research question was: What are the communication experiences of international nurses who recently participated in a 13 -week accent modification program?

\section{METHOD}

\subsection{Setting}

The Magnet $($-designated 912 bed, not for profit, faith-based, acute care hospital located in Southwest Texas was the study site. The hospital employs more than 4,000 staff, of which 1,500 are nurses. International nurses at the institution comprised about $30 \%$ of total nurses. The accent modification program was conducted in the study institution from July 20, 2011 to October 14, 2011.

\subsection{Participants}

Sixteen international nurses participated in the accent modification program. Three withdrew from the program and 13

Published by Sciedu Press completed the program. At the time of withdrawal or completion, the nurses were informed that a qualitative study that aims at exploring their communication experiences would be conducted soon. The researcher decided to include those who withdrew because each participants experience was found to be unique and important to this study. All of them expressed interest in becoming part of the study and willingness to stay in touch with the investigator until recruitment for this qualitative study began. Two participated in the pilot study and 14 participated in the main study. Inclusion criterion was international nurses at a tertiary care Magnet $($-designated hospital in southwest Texas at the time of the training who participated in the 13-week accent modification program.

\subsection{Data collection}

The semi-structured, in-depth interviews were held at a private location agreed upon by the participants and the researcher. Code names were used. Interviews were audio recorded, transcribed verbatim, and verified for accuracy. All data were password protected, viewed only by the researcher, and kept in locked cabinets/desks. The participants were informed that they could withdraw at any time. Following the completion of the interviews, the participants received small gift to demonstrate appreciation for their participation. The summary of the results was mailed or e-mailed to them upon request.

An interview guide was used to standardize the process of data collection. Semi-structured interview questions were used for this study. The study participants were asked a series of questions to describe their communication experiences after participating in a 13 -week accent modification program. The demographic form included age, gender, education level, ethnicity, country of origin, language (s) they used as a child, years in the U.S, language (s) they usually speak at home, and in what language they usually think.

\subsection{Analysis of data}

Fourteen international nurses who undergone the 13-week long accent modification program participated in a single, audio-recorded interview (45 to 60 minutes). The training was conducted by a certified speech therapist. International nurses in this study were defined as nurses who spoke English as a second language. Participants were predominately female (93\%). Nationalities included Filipinos (50\%), Vietnamese $(7 \%)$, Chinese (7\%), Nigerian (14\%), Zimbabwean $(7 \%)$, Korean $(7 \%)$, and Indian $(7 \%)$. The majority $(71 \%)$ were prepared at the BSN level of education. Age ranged from 27 to 61 years with a mean of 57.5 years. The mean years lived in the U.S. and speaking English were 18.5 years and 32 years respectively. Half of the participants (50\%) 
reported to speak both native and English at home. Fortythree percent reported to use both English and native language to speak with their friends, English (43\%) and native $(14 \%)$. Almost half of them (43\%) reported thinking in their native language and the rest reported to think both in English and native language. Once themes had been obtained, the researcher approached three participants to validate if the identified themes were consistent with their experiences. The research proposal was submitted to the hospital and university Institutional Review Boards (IRBs) for approval. Participation was entirely voluntary and had no bearing on employment.

The responses to the following 8 questions were documented:

Question 1: Describe a recent professional communication experience that you have had with a patient, Question 2: a fellow nurse, Question 3: a physician, Question 4: during a phone conversation, Question 5: a patient family member, Question 6: an unlicensed personnel, Question 7: an allied health professional and, Question 8: a large group of people.

After each question, it was asked:

a. What made the communication experience successful?

b. What made the communication experience less successful?

c. In what way was this communication experience different from before the accent modification program?

d. In what way was this communication experience similar from before the accent modification program?

e. What did you do differently in the communication than you would have before taking part in the accent modification program?

\section{Findings}

From the analysis of the transcripts, 200 relevant statements and 6 themes emerged.

\section{Theme 1: I have the tool I need: The tool to overcome my accent related unintelligibility}

Many participants felt that the program helped them understand why people have difficulty understanding them. One participant stated, "before the accent modification program, I knew I had some accent problem but I could not pin point what it exactly was... I did not know how to improve it, but after the program I am very aware of my accent and I am aware of my pronunciation challenges". All of the participants felt they learned some strategies/skills to deal with their accent problem. One strategy/skill used by all the participants to make their communications successful was "slowing down". "... when we are busy, it is hard to remember to slow down then you get misunderstood a lot but if I maintain eye contact, speak slowly ... But the problem is when we are thinking about something else and talking at the same time it becomes ineffective communication".

Other skills/strategies learned were putting the right stress on the right syllable, pronouncing words until the end, using appropriate voice projection, maintaining eye contact, and paying attention to how native speakers speak. One participant described successful communication with patients "... I remember in the class we talked about when you talk to people, especially the patient and family member, try to direct your voice to that direction and maintain eye contact." One participant confidently described her communication experience with physicians "I talk to them directly, I make eye contact, I speak slowly and clearly and pronounce my words ... they look at you with more respect and you have more confidence and they treat you more as a professional..."

Participants felt that conversation with a large group has gotten much better. One participant stated, "Large group used to be a major problem... I was valedictorian of my class and we had to give a speech at the pinning ceremony and I thought I was going to die... but now I had to give... a speech at my church the other day. I was... engaging... moving around making sure I am getting everybody's attention. They understood me perfectly."

\section{Theme 2: I am self-assured: Self-assured that I can be understood}

In this cluster, the participants felt that the program improved their intelligibility and boosted their confidence. One participant confidently described her communication experience “... with my patients I guess I have more confidence. I can express myself better.” Another stated, "... I had some problems [pronouncing]... the word blood pressure... carotid artery... when I am communicating with doctors now I am more confident because I know I can pronounce those words."

\section{Theme 3: I speak with intention: Intention of getting my message across}

The participants focused on the shift in their focus from just talking to talking with purpose. One participant stated "... what I did after the class is that I want to make sure... I should communicate with them [patients] slowly and clearly so they can understand me... I am very conscious now of what I'm saying..." Another participant stated how she took her time to get message across when a family member called to get an update. "I try to explain it in a better way, try to pronounce it you know the way that the person would understand what I am saying and I can say recently most of my patients say oh! Where are you from? Did you learn English in your country? You speak English well so it helps really".

ISSN 1925-4040 E-ISSN 1925-4059 


\section{Theme 4: I want to involve: Involve in various quality improvement projects and others opportunities}

Participants focused on their readiness to take on various voluntary activities which they thought unthinkable before the program. One participant stated "I served as a code validator... right now I am glucometer validator and it is going well. Before [the program] when we even have huddle in the morning I didn't want to talk". Another participant felt the program motivated her to advance her career. "This made a big difference in my life you know being able to talk to people in a second language it was you know I would say it obstructed me from doing you know from moving ahead and now I think I can." Another participant stated that she turned down opportunities. "Yes, I did. If I didn't really had to, I would let other people speak."

Theme 5: My accent is part of who I am: Part of who I am that attempting to modify my accent is a deliberate journey

Participants viewed the accent modification as a lifelong learning. They realized the program is just the start, not an end and they need to continue working on improving their communication. One participant explained how her accent has been part of her all her life and does not expect it to go away "...I have been talking this way for how many years and I just had you know that accent modification for a few months but at least it helped me you know like express or say the words... correctly but I still have the accent of course...." Another participant stated accent modification is a lifelong learning "I think there are still some words I cannot pronounce correctly and I know I have to work on it."

Theme 6: I am not an introvert: That is just one of my ways to minimize miscommunications and misunderstandings

The participants focused on their openness to talk to people after the program. The participants felt that before the program the only tool they had to tackle their accent-related challenges was to minimize their conversations with people. One participant stated "Now I am networking with people more... before you know I tend to talk to my own kind I mean people from the same country... Before I kind of like shy. I didn't talk to a lot of people but now I feel like I talk more with my co-workers and I kind of have more friendship with them because I talk more, opened myself to them but before kind of like hold myself up...". "Sometimes the quietness comes across as unapproachable or unfriendly but, it is because I am afraid when I say something they are not going to understand me".

Published by Sciedu Press

\section{Discussion OF THE FINDINGS}

Although there is literature related to communication challenges of the international nurses, limited intervention research has been published regarding how to improve the linguistic proficiency of international nurses. A systematic literature review conducted by Zizzo and Xu (2009) ${ }^{[18]}$ resulted in only one published intervention study by Yahes \& Dunn (1996) ${ }^{[19]}$ designed for post-hire international nurses to improve communication skills through a course that addressed therapeutic and verbal/non-verbal communication with a cultural component.

A multi-site quasi-experimental study conducted by Shen et al. (2012) ${ }^{[2]}$ revealed a statistically significant difference in percentage of pronunciation errors reduction for words spoken, between international nurses who underwent a 10week accent modification program and the control group who received a socio-cultural workshop intervention. Similarly a pre and post-test design study conducted in a magnet hospital in Southwest, Texas shows that post intervention pronunciation errors were significantly lower $(p<.0001)$ than pre-intervention pronunciation errors in four areas: Carrier sentences, passage, medical terms and shift report. The findings of this study suggested that accent modification program helped the international nurses to speak clearly. ${ }^{[16]}$ However, both studies did not discover how the participants utilized the skills in their daily communications and their perception of the program's effectiveness. This study suggested that the 13-week accent modification program was effective in improving the international nurse's communication experiences with patients, family members, fellow nurses, physicians, and allied health professionals. Moreover, the program appeared to be effective in improving the international nurse's communication experiences with larger groups of people.

Aspects of Theme 5 (My accent is part of who I am: Part of who I am that attempting to modify my accent is a deliberate journey) have been mentioned by Shen et al. (2012). ${ }^{[2]}$ Taking into consideration the nonlinear nature of international nurses' communication challenges, Shen et al. (2012) ${ }^{[2]}$ asserted that international nurses may not overcome linguistic barriers overnight (p. 26). Similarity, Baron as cited in Gorman (2007), ${ }^{[20]}$ a linguistic professor at the University of Illinois asserted that modifying an accent takes years of interaction with native English speakers. Under Theme 1 (I have the tool I need: The tool to overcome my accent related unintelligibility) one of the strategies the participants learned was to pay attention to how native speakers pronounce words, and in Theme 5 they indicated that they were aware that accent modification is a process not an end. One participant felt that accent modification program is not enough to be successful and this has also been echoed by Shen et al. 
$(2012)^{[2]}$ that overall communication effectiveness is multifactorial. Theme 1 (I have the tool I need: The tool to overcome my accent related unintelligibility) and Theme 2 (I am self-assured: Self-assured that I can be understood) in this study revealed that the participants were aware of the threats of communication breakdowns due to accented speech and focused on the skills learned to avoid misunderstandings and communication breakdowns.

Shen et al. (2012) ${ }^{[2]}$ asserted that passing standardized tests does not appear to guarantee communication effectiveness on the job in the real world. This was consistent with this study that despite their passing status of English tests, the participants felt they needed support to overcome their accentrelated communication challenges. The participants felt that the program not only helped them to understand why they were misunderstood but also how they can overcome the challenge (Theme 1).

Shen et al. (2012) ${ }^{[2]}$ reported that accented speech could result in unintelligibility, which consequently could lead to communication breakdown. Similar findings were discovered in the current study. Participants shared their unsuccessful communication experiences before the program. Many stated that they were having difficulty pronouncing medication names, physician and patient last names, and various medical terms. Shen et al. (2012) ${ }^{[2]}$ reported that inaccurate tongue positioning, intonation, and/or misplacement of syllable stress in words are some of the factors that results in accented speech and incorrect pronunciation. In this study, placing stress on the right syllable came up several times (Theme 1). Today's practice setting is complex and fast paced. ${ }^{[21]}$ The participants emphasized the importance of making a habit to speak slowly but they also acknowledged how this could be a challenge during emergency situations.

Yahes and Dunn (1996) ${ }^{[19]}$ reported a decrease in the number of overall incident reports, fewer communication-related complaints from physicians and staff, and improved collegiality among staff after a similar linguistic intervention. Similarly in this study, Theme 1 (I have the tool I need: The tool to overcome my accent related unintelligibility) and Theme 2 (I am self-assured: Self-assured that I can be understood) and Theme 6 (I am not an introvert: That is just one of my ways to minimize miscommunications and misunderstandings) indicated that the nurses felt they make fewer pronunciation errors as evidenced by validation from others and hardly repeating themselves. Under theme 6 they reported that they are more open talking to people and engaging in conversation which may improve the collegiality among staff.

Some participants focused on the confidence they gained from the program. Even if there were still some words they could not pronounce properly they proceeded with confidence rather than avoiding the conversation. They applied the principles they learned and if that did not work, they asked native speakers to pronounce it for them.

Delegation is one of the difficult skills nurses should learn. Delegation is a complex nursing skill that requires sophisticated clinical judgment and final accountability for patient care. ${ }^{[22]}$ Under Theme 6 (I am not an introvert: That is just one of my ways to minimize miscommunications and misunderstandings) one participant stated one strategy she used to avoid miscommunications was avoiding delegation. In a study by Clarke and Garret (2004), ${ }^{[23]}$ native English speakers who were exposed to English sentences produced by non-native speakers (Spanish-and Chinese-accented speech) demonstrated adaptation to accented speech. Some participants in this study felt that people who speak with an accent understand them a little better and showed more patience and understanding towards them than native English speakers.

\section{SUMMARY}

All the participants agreed that the program provided them helpful tools related to their pronunciation challenges while boosting their confidence and self-esteem. Many felt ready to step out of their comfort zones to engage in professional conversations and assume leadership roles. Some concerns were the challenge of consistently applying the learned skills and sliding back to previous ways of pronunciations. Many participants felt that the program helped them understand why some of their words were unintelligible and what can be done to improve their intelligibility. Before the program, they tried to avoid miscommunications by minimizing conversations and avoiding challenging words.

All participants felt that slowing down was the most important skill they learned. However, some participants voiced their concern that in this fast paced and complex clinical setting slowing down may not always be possible. Other skills learned and applied/tested were voice projection, eye contact, putting the right stress in the right syllable, and pronouncing words till the end. Many stressed the confidence they gained and their ability to be understood and get their messages across. However, all of them felt that modifying a person's accent is a process and remembering to apply the skills and the principles consistently is critical and challenging as well.

\section{Conclunions AND implications}

Findings from this study have important implications for practice, education, and research regarding safety and quality of care, as well as for the adjustment, job satisfaction, and career advancement of international nurses. Successful com- 
munication is often hindered by accent which cause words and/or phrases to be unintelligible. For international nurses, precise and intelligible communication skills are crucial for their professional success.

To ensure patient safety and quality care, it is critical that hospitals and other clinical settings incorporate accent modification programs into the international nurses' transition and ongoing support programs. Unfortunately, health care organizations rarely address language challenges (Zizzo \& $\mathrm{Xu}, 2009)$. The accent modification program needs to target both current and new international nurses who have communication challenges due to their accented speech. It was evident in this study that after more than 30 years in the U.S., accent could still be a barrier to effective communication. Many participants in this study suggested making the program available not only to nurses, but also to unlicensed personnel, physician, and allied health professionals.

Since willingness and practice is a key to success it is important employers come up with strategies to make international nurses feel that it is a win-win situation to participate in such program. This is important because it may have a great financial implication for employers. In this study, participants felt that it would be helpful to bring back the participants to class every so often to reinforce the skills. Employers may need to consider some refresher classes to reinforce the skills. Employers may consider having shorter programs to cut costs

In this study, many participants felt that they did not need to repeat themselves after the program. They felt the clearer communication saved them time to take care of other tasks and activities. This could influence agencies outcome in a positive way. This study demonstrated that the accent modification program helped the participants to engage in various roles and in becoming more confident in professional communication. This may have a positive return on investment and make a difference in the engagement gallop survey.

If employers fail to provide support programs including accent modification, international nurses will continue to use

\section{REFERENCES}

[1] Polsky D, Ross SJ, Brush BL, et al. Trends in characteristics and Country of origin among foreign-trained nurses in the United States, 1990-2000. American Journal of Public Health. 2007 May; 97(5): 895-898. https://doi .org/10.2105/AJPH. 2005. 072330

[2] Shen JJ, Covelli M, Xu Y, et al. Effects of a short-term linguistic class on communication competence of International nurses: Implications some ineffective ways to overcome their challenge which could in turn affect patient outcome and work dynamics. For instance, they may avoid delegations, avoid socialization, and avoid voluntary activities. It is important that managers be attentive and support their international nurses. The 13week accent modification program appears to improve the communication skills of international nurses regardless of age, gender, national origin, and length of stay in the U.S.

Findings of this study may provide a body of knowledge to academia in its effort to support international student nurses who face enormous communication challenges. Nursing students may benefit from accent modification programs offered by a speech pathologist. Nursing and other allied healthcare students who participated in 12 (non-credit) one-hour accent modification classes demonstrated enhanced perceived self-esteem, and improved overall communication skills. ${ }^{\text {[24] }}$ A large-scale study that utilizes mixed method should be conducted to validate the findings of this study. It is suggested that a further research study be conducted 2 years after program completion to validate the findings.

It is well documented that language and communication skill is one of the challenges that face international nurses. Although many learn some basic or formal English and pass English exams before immigrating the U.S., unfamiliarity with slang/idioms or variations in vocabulary and pronunciation can make communication difficult and hinder these nurses' advancement and lower their self-esteem and confidence. International nurses attend the accent modification program to tackle one of their communication challenges: Pronunciation.

\section{ACKNOWLEDGEMENTS}

The author would like to thank Dr. Sandy Cesario, dissertation chair and Dr. Anne Young and Dr. Lene Symes, committee members for providing with insightful feedback and expert guidance. Heartfelt thanks goes to Dr. Joyce Simones for her support and encouragement.

\section{CONFLicts OF InTEREST Disclosure}

The author declares that there is no conflict of interest. for practice, policy, and research. Nursing Economics. 2012 Jan; 30(1): $21-28$

[3] Ea EE. Facilitating acculturation of foreign-educated nurses. Online Journal of issues in Nursing. 2008 Jan; 13(1).

[4] Adeniran R, Rich V, Gonzalez E, et al. Transitioning internationally educated nurses for success: A model program. The Online Journal of Issues in Nursing. 2008 May; 13(2). 
[5] Aiken L. U.S. nurse labor market dynamics are key to global nurse insufficiency. Health Services Research. 2007 Mar; 42(3): 1299-1320. https://doi.org/10.1111/j.1475-6773.2007.00714.x

[6] Xu Y. Speak for success: A pilot intervention study on communication competence of post-hire international nurses. Journal of Nursing Regulation. 2010 Jul; 1(2): 1-6. https://doi.org/10.1016/S2 155-8256 (15) 30350-1

[7] Xu Y, Kwak C. Characteristics of internationally educated nurses in the United States. Nursing Economic. 2007 Nov; 23(5): 233-238.

[8] Xu Y. Communicative competence of international nurses and patient safety and quality of care. Home Health Care Management \& Practice. 2008a Mar; 20(5): 430-432. https ://doi .org/10.117 $7 \% 2 \mathrm{~F} 1084822308316162$

[9] Xu Y. Facilitating adaptation of international nurses: Need for an evidence-based transition and integration program. Home Health Care Management \& Practice. 2008b Feb; 20(2): 199-202. https: //doi.org/10.1177\%2F1084822307309064

[10] Scott DF. New trends in foreign nurse recruitment. Florida Nurse. 2008; 56(1): 18-19.

[11] The Joint Commission. Sentinel Event Data Root Causes by Event Type. 2010. Available from: http: //www.jointcommission.org/assets/1/18/SE_RootC ausesEventType2004_4Q2010.pdf

[12] Xu Y. Strangers in strange lands: A meta-synthesis of lived experiences of immigrant Asian nurses working in Western countries. Advances in Nursing Science. 2007 Jul; 30: 246-265.

[13] Xu Y, Gutierrez T, Kim SH. Adaptation and transformation through (un)learning: Lived experiences of immigrant Chinese nurses in U.S health care environment. Advances in Nursing Science. 2008 Apr; 31(2): E33-E47.

[14] Compton AJ. Compton Phonological Assessment of Foreign Accent, Institute of Language, San Francisco, CA. Carousel House. 2002.

[15] Carr SM, DeKemel-Ichikawa K. Improving Communication Through Accent Modification: Growing The Nursing Workforce. Journal of Cultural Diversity. 2012 Fall; 19(3): 79-84. Available from: https://www.ncbi.nlm.nih.gov/pubmed/23155893

[16] Belay HA. Accent Modification to Improve International Nurses' Communication with Physicians, Hospital Staff and Patients, Podium Presentation at the 38th Annual Conference of The Transcultural Nursing Society, Orlando, FL, MN. 2012.

[17] Polit D, Beck C. Nursing research: Generating and assessing evidence for nursing practice. Philadelphia: Lippincott Williams \& Wilkins; 2008.

[18] Zizzo KA \& Xu, Yu. Post-Hire Transitional Programs for International Nurses: A Systematic Review, The Journal of Continuing Education in Nursing. 2009 Feb; 40(2): 57-64. https ://doi .org/ 10.3928/00220124-20090201-02

[19] Yahes E, Dunn AK. Encul-turaltion of foreign nurse graduates: An integrated model. The Journal of Continuing Education in Nursing. 1996; 120-123. Available from: https://www.ncbi.nlm.nih.g ov/pubmed/8715879

[20] Gorman A. Surge in accent reduction classes speaks volumes; immigrants and others wanting to sound more American flock to the courses but some linguists are skeptical. Los Angeles Times. 2007 Oct 23. Available from: https://search. proquest.com/docv iew/422168332? accountid $=14048$

[21] Ebright P. The Complex Work of RNs: Implications for Healthy Work Environments, OJIN: The Online Journal of Issues in Nursing. 2010 Jan; 15(1). https://doi.org/10.3912/0JIN.Vol15No01 Man04

[22] Weydt A. Developing Delegation Skills. OJIN: The Online Journal of Issues in Nursing. 2010 May; 15(2). https ://doi .org/10. 391 2/OJIN.Vol15No02Man01

[23] Clarke CM, Garret MF. Rapid adaptation to foreign-accented speech. The Journal of the Acoustical Society of America. 2004 Mar; 116(6): 3647-3658. https://doi.org/10.1121/1.1815131

[24] Freysteinson WM, Adams JD, Cesario S, et al. An accent modification program. Journal of Professional Nursing. 2017 Jul; 33(4): 299304. https://doi.org/10.1016/j.profnurs . 2016.11.003 